\title{
Agreement in Magahi Complex Predicate
}

\author{
Nilu Rakesh (Corresponding Author) \\ Department of Humanities and Social Sciences, Indian Institute of Technology Patna, \\ Patliputra Colony, Patna- 800013, India \\ Tel: 91-767-773-2568 E-mail: nilu@iitp.ac.in/nilu.linguistics@ gmail.com

\begin{abstract}
Rajesh Kumar
Department of Humanities and Social Sciences, Indian Institute of Technology Madras,

I.I.T. Post Office, Chennai-600036, India

E-mail: thisisrajkumar@gmail.com
\end{abstract}

Received: December 21, 2012 Accepted: January 14, 2012 Published: February 28, 2013

doi:10.5296/ijl.v5i1.3304 URL: http://dx.doi.org/10.5296/ijl.v5i1.3304

\begin{abstract}
Verb carries a lot of information along with the information about agreement. Suffixes attached to verbs demonstrate the information about agreement. This paper focuses on complex predicate, which takes two elements but function as a single verbal unit. The paper shows how agreement which is a universal phenomenon of language interacts with complex predicate. Since complex predicate is a single verbal unit, agreement does not discriminate between simple verb and complex predicate. Agreement in Magahi has unique features in the sense that case markers are opaque in agreement system. The role of addressee component and honorific and non-honorific factor attached to listener/speaker play an important role in agreement between argument and light verb of complex predicate. Magahi negotiates its agreement in terms of person and honorificity.
\end{abstract}

Keywords: Agreement, Complex Predicate, Magahi, Honorificity 


\section{Introduction}

Complex Predicate is an aerial feature of most of the South Asian languages (Butt 1995, Hook 1974). Complex Predicates are of two types; conjunct verbs and compound verbs. Conjunct verbs are a combination of a noun or an adjective and a verb. On the other hand, compound verbs are a combination of a verb and a verb. In either case the first element of complex predicate does not carry any inflection, and it occurs in root form whereas, the second element which is also referred to as a light verb carries inflection markers of tense, aspect, modality, person, and honorificity (specifically in Magahi).

Agreement is a significant component of language. Verb plays an important role in it. 'Agreement' is the grammatical phenomenon in which the form of one item forces a second item in the sentence to appear in a particular form (Baker 2008). Agreement feature occurs between two elements of the sentence, i.e. between determiner and argument, between adjective and argument, and verb and argument. This paper is focused on the argument and verb agreement. Verbs occur in different forms in a sentence such as simple verb, causative verb, composite verb, conjunct verb, and compound verb. An attempt is made to study the agreement feature in context of simple verb in Magahi (Verma 2002), but the agreement features in context of Magahi complex predicate has not been discussed in detail. This paper is an attempt to study the agreement feature of Magahi in relation to complex predicate. It is interesting to note how complex predicate with two elements but functioning as a single element works in agreement with the argument of the sentence. The paper highlights the features and uniqueness of agreement feature in Magahi complex predicate.

The paper consists of six major sections. The first section is of Introduction. It gives description about agreement system in Hindi (a major South Asian language) and Magahi. The second section presents a brief discussion on Magahi as a language and complex predicate in Magahi. The third section takes us to the discussion on agreement feature in context of Magahi. The fourth section shows how agreement feature works in Magahi complex predicate. The fifth section deals with the structural representation of Magahi complex predicate in Principles and parameters. The sixth section is of conclusion.

\section{Magahi and Complex Predicate}

Magahi is an Indo-Aryan language. It is genetically related to the eastern group of languages and descendents of Magadhi Prakrit. It is geographically placed in the border region with eastern Hindi varieties with a different historical origin. Magahi is spoken in the area which formed the core of the erstwhile ancient kingdom of Magadha- the modern districts of Patna, Nalanda, Gaya, Jahanabad, and a few more. It is one of the widely spoken languages in Bihar, along with Bhojpuri and Maithili. It is a head final language with Subject Object Verb order 
in a sentence. One of the major differences between Magahi and other Indo Aryan languages is that it has no ergative case. However, Magahi follows the in-situ pattern of movement.

Complex Predicate in Magahi is a combination of a noun/ adjective / verb and a light verb. These (N/A/V and light verb) together behave like a single unit of verb. Magahi confirms both the types of the complex predicates; compound verbs and conjunct verbs. Compound verbs are verbal predicate composed of two verbs $(\mathrm{V} 1+\mathrm{V} 2)$, as in (1). On the other hand, conjunct verbs are verbal predicate composed of Noun+ Verb (V2) and Adjective+ Verb (V2) sequence, as in (2) and (3) respectively.

Compound Verb $(\mathrm{V}+\mathrm{V})$

1. raam chat se gir gelaii

Ram roof from fall go.perf.3.NH

'Ram fell down from the roof.'

Conjunct Verb $(\mathrm{N}+\mathrm{V})$

2. giitaa aapan laikaban par dheyaan deba haii

gita her children on attention give be.pr.NH

'Gita pays attention to her children.

Conjunct Verb $(\mathrm{A}+\mathrm{V})$

3. okar gharwa ham kal saafkarle haliaii

his/her room I yesterday clean do.perf be.pt.NH

'I cleaned his/her room yesterday.'

In example (1), the main verb gir 'fall' and light verb gelaii 'went' together form the compound verb construction. In example (2), the light verb de 'give' gets bleached with the noun dheyaan 'attention' and together forms the $\mathrm{N}+\mathrm{V}$ conjunct verb construction. In example (3), the adjective saaf 'clean' and light verb karle 'did' together form the A+V conjunct verb construction.

V2 represents light verb. In Magahi, in case of complex predicate, the first element (N/A/V1) always carries root form whereas V2 carries inflections and gives information about person, tense, aspect, honorificity and so on. There are about twenty five light verbs in Magahi such as khaa 'eat', maar 'kill/ beat', de 'give', jaa 'go', baiT 'sit', $u T$ 'rise', ho 'be/ become', aa 'come', le 'take', kar 'do', lag 'feel', cal 'walk', nikal 'escape', sak 'can', rah 'live', cuk 'finised', paR 'fall/lie', paa 'achieve', rakh 'keep', kaaT 'cut', $u R$ 'fly', laR 'fight', kaaDh to take out', bhar 'full', and khol 'open'. The light verb combination gives new meaning and considered as semi-idiomatic construction. The transitive and intransitive feature of light verb is lost. 


\section{Agreement in Magahi}

Agreement is a universal feature of languages of the world. It becomes parametric in the sense of the features involved in agreement in different languages. In South Asian languages, verbs agree with subjects in person, number and gender. Magahi is different from many of the South Asian languages in the sense that it exhibits agreement in terms of honorificity. Before we discuss the agreement system of Magahi, let us take a look at the agreement system of one of the most dominant South Asian language, namely Hindi. In Hindi, the verb exhibits agreement in person, number, and gender. It does not exhibit agreement with the arguments which are lexically case marked. If the subject does not have an overt lexical case marker, agreement occurs between subject and the predicate as in (4). If the subject is lexically case marked, then the agreement takes place with one of the argument of the predicate that does not carry a lexical case marker as in (5). There occurs a default agreement on the verb if all the arguments of a sentence is lexically case marked as in (6).

\section{Hindi}

4. raam kitaab paDh-taa thaa

Ram.M book.F.Sg read-HAB.M.Sg be.Pt.M.Sg

'Ram used to read book.'

5. raamne kitaab paDh-ii thii

Ram Erg book.F.Sg read-F.Sg be.Pt.F.Sg

'Ram had read the book.'

6. raam ne phal ko caaku se kaaTaa

Ram Erg fruit Acc knife by cut.M.Sg

'Ram cut the fruit with knife.'

In example (4), the subject of the sentence does not carry any lexical case markers, hence the main verb paDhtaa 'read' and auxiliary verb thaa 'was' agree with the subject of the sentence 'Ram'. In example (5), the main verb paDhii 'read' and auxiliary verb thii 'was' agree in number and gender with the object of the sentence (argument of the predicate), as it carries no lexical case marker. In example (6), all the three arguments of the sentence carry lexical case markers; therefore, the verb carries the default agreement.

Let's turn to Magahi for an understanding of Magahi agreement system. Magahi is quite different with its own uniqueness from many of the South Asian languages. For Hindi, structural case and verbal agreement are intimately connected as structural case can be assigned via Agr positions (Mahajan 1989, 1992). But this is not the case with Magahi. Magahi agreement system is case opaque. Case marking has no effect on the agreement. The 
agreement in Magahi is navigated through person and honorificity. Lets' have a brief look of the varying auxiliary items with person and honorificity, as in (7).

7. Different auxiliary markers in different person, number, tenses and addressee components:

\begin{tabular}{|l|l|l|l|}
\hline $\begin{array}{l}\text { PERSON } \\
\text { TENSE }\end{array}$ & FIRST PERSON & SECOND PERSON & THIRD PERSON \\
\hline Present Tense $(\mathrm{H})$ & $\begin{array}{l}\text { hii, hiiN, hiaii } \\
\text { hiwa }\end{array}$ & $\begin{array}{l}\text { ha, hahuu, hathin, } \\
\text { hathan }\end{array}$ & $\begin{array}{l}\text { hain, hath, hathun, } \\
\text { hathin, hakhin }\end{array}$ \\
\hline Present Tense $(\mathrm{NH})$ & hiau, hiyo & he, hahii & haii, hau \\
\hline Past Tense $(\mathrm{H})$ & hali, haliain & hali, halan, halthin & $\begin{array}{l}\text { halan, halthin, } \\
\text { halthu, halthun }\end{array}$ \\
\hline Past Tense $(\mathrm{NH})$ & haliai, haliau & hale, halhiiN & hal, halaii, halau \\
\hline Future Tense $(\mathrm{H})$ & $-b,-m$ & $-b,-m$ & -tan \\
\hline Future Tense $(\mathrm{NH})$ & - & $-e$ & -ta, -taii \\
\hline
\end{tabular}

The above table shows the variation in agreement markers such as person and honorificity in the context of tense in Magahi.

\subsection{Honorificity and Agreement in Magahi}

In Magahi, the agreement between the argument and verb depends on two things, i.e. agreement based on person and agreement based on honorificity or non-honorificity of the addressee component. These two features of agreement are discussed below. The verb shows agreement with argument (either subject or object) in person. Let's consider the examples in (8), (9), and (10).

8. ham jaa hii

I go be.pr.1

'I go.'

9. tuu jaa he

you go be.pr.2

'You go.'

10. raam jaa haii

Ram go be.pr.3

'Ram goes.' 
In example (8), the agreement between verb and subject is on person. The subject in third person takes the auxiliary form in third person. In example (9), the second person subject takes the auxiliary form in second person. In the same way in (10), the subject and auxiliary verb agrees in third person feature.

The verb shows agreement with the argument (either subject or object) based on addressee component. The selection of auxiliary or suffix attached to the verb depends on the honorificity or non-honorificity of the addressee. The examples in (11a-d) illustrate this.

11. a. $t u$ jaait he

you.NH going be.pr. NH.

b. tu jaait ha.

you.NH going be.pr.H.

c. apne jaait hii/hath.

you.H going be.pr.H.

d. apne jaait hiaii/hathan/hathin.

you.H going be.pr.H

'You are going.'

The examples (11a-d) show the inflection on auxiliary verb on the basis of honour given to addressee. In (11a) the non-honorific auxiliary he is used which shows agreement with the subject where the subject $t u$ is non-honorific pronoun. In (11b) the honorific auxiliary ha is used to show the honour for subject. In (11c) more honorific auxiliary hii/hath is used which agree with the second person honourable subject. In (11d) the highest degree of honorific auxiliary hiaii/hathan/hathin is used to show more honour to the subject.

\section{Agreement and Complex Predicate in Magahi}

This section begins with the hypothesis in mind that agreement system in Magahi in the context of complex predicates would work in a similar fashion as it does in simple verb forms. Before moving into Magahi complex predicate, lets' see this feature in other Indo-Aryan Languages such as Hindi, Bengali and Marathi. Bhatt (2008) reports that the verbal agreement goes with the subject as far as it can but when the subject does not have agreement features, verbal agreement targets the next highest argument. He reports that normally the noun in $\mathrm{N}+\mathrm{V}$ construction agrees with the light verb, if the other arguments of the sentence are case marked. But sometimes it doesn't and in such cases the noun is not treated by the grammar as an argument and is invisible for agreement as in (12). Paul (2004) points out that the simple finite verb forms agree with the subject in person in Bangla. In periphrastic compounding, V1 is inflected for the conjunctive participial form and V2 is inflected for tense, aspect and person morphology. The subject argument agrees with the V2 in person (13) 


\section{Macrothink}

in Bangla. Deoskar (2006) points out that in the context of Marathi complex predicate construction, the light verb has to obligatorily agree with a non-case marked subject or object DP as in (14).

\section{Hindi}

12. a. raam-ko aatif-kii yaad aaii

Ram-Dat Atif-Gen memory.F come.Perf.F

'Ram thought of Atif.'

b. raam-ne aatif-ko yaad kiyaa

Ram-Erg Atif-Acc memory.F do.Perf.M

'Ram thought of Atif.'

(Bhatt 2008: 3)

Bengali

13. ami bhat khe-e ni-lam

I rice eat-cp take-1.Pt

'I took rice (self-beneficiary).'， (Paul 2004: 64)

\section{Marathi}

14. gita-ni mohan-la chitthi lih-un dili

Gita-Erg Mohan-Dat letter.F write-Part give.Pt.F

'Gita wrote a letter for Mohan.'

(Deoskar 2006: 6)

In (12b), the light verb kiyaa 'did' does not agree with any of the three arguments (i.e. two external arguments 'Ram' and 'Atif'; and one internal argument yaad 'memory. Generally, when the external arguments occur with case markers, then the light verb agrees with internal argument. In example (12a), both internal argument yaad 'memory' and light verb aaii 'came' agrees. But it is not so in (12b), the internal argument yaad is feminine but kiyaa is masculine. It takes the default agreement markers of third person, masculine, and singular. Here, in (12b), yaad is not considered as internal argument for agreement. In (13), the subject ami 'I' agrees with the V2 neoa 'take' in person. In (14) the light verb dili 'gave' agrees with the direct object citthi 'letter' in gender.

In Magahi the agreement is reflected through inflection attached to the last verb, i.e, either main verb or light verb or auxiliary of the sentence. In Magahi complex predicate Noun/Adjective/Main verb always carry root form or in participial form and light verb carries inflections and gives information about person, tense, aspect and so on. The subject verb agreement is reflected through suffix attached to light verb in person and honorificity as in 
(15), (16) and (17). There is no agreement on the basis of number (18a-b) and gender, as in (19a-b).

\section{Magahi}

15. ии cal gelaii/gelthin

he walk go.pt NH/go.pt.H

'He went away.'

16. tии cal gele/gela

you walk go.pt.NH/go.pt.H

'You went away.'

17. uu madad karlaii/ karlathiin

he help do.pt.NH/do.pt.H

'He helped.'

18. a. raam ghare cal gelaii

Ram.sg home walk go.pt.NH

'Ram went home.'

b. ohnii ghare cal gelaii

they home walk go.pt.NH

They went home.'

19. a. laikabaa khaa lelaii

boy eat take.pt.NH

'The boy ate.'

b. laikiyaa khaa lelaii

girl eat take.pt.NH

'The girl ate.'

In examples (15), (16) and (17), the agreement is between subject and light verb only. The light verb takes different suffixation on the basis of person and honorificity. In example (15) and (16) representing compound and conjunct verb respectively, the suffix -aii takes third 
person and non-honorific agreement. In the same way, in example (17), the suffix $-e /-a$ takes second person and honorific/non-honorific agreement. In example (18a-b), we see that there is same complex predicate cal gelaii 'went' used for both singular 'Ram' and plural 'they' subject. There is no change on light verb based on number. In example (19a-b), the complex predicate khaa lelaii 'ate' remains same for masculine and feminine subject in (19a) and (19b) respectively.

\subsection{Honorific Agreement and Complex Predicate in Magahi}

Verbs in Magahi agree with both subject and object in person and honorificity. The sentence in (20) shows the light verb agreeing with subject. The sentences in (21) shows light verb agreeing with object. The sentences in (21a) and (21b) show the simple verb agreeing with object. The light verb of complex predicate in Magahi agrees with both the subject and object in person and honorificity, as in case with examples in (20) and (22).

Verb agreement with subject

20. raam khaanaa khaa le-l-ai/le-l-kai

Ram food eat take-perf.NH

'Ram has taken the meal.'

Verb agreement with object

21. a. sitaa okraa paDh-al-kai

Sita him.NH read-perf-NH

'Sita taught him.'

b. sitaa unkhaa paDh-al-kain

Sita him.H read-perf-H

'Sita taught him.'

22. a. ham apne ke jaae deliain

I you.H ACC go give.pt.H

'I let you go.'

b. ham toraa jaae deliau

I you.NH go give.pt. NH

'I let you go.'

In (20), the verb le-l-aille-l-kai 'take' agrees with the subject 'Ram' in both person and honorificity. In (21a), the verb paDh-al-kai 'taught' agrees with the object in honorificity. In Magahi suffix -kai in paDh-al-kai is non-honorific marker. In (21b), the verb paDh-al-kain 
'taught' agrees with the object unkhaa 'him' which carries honour. The suffix -in in paDhal-kain is honorific marker. In (22a) and (22b), the light verb haliain and haliau agrees with second person honorific apne and second person non-honorific toraa as object of the sentences respectively.

The agreement between argument (either subject or object) and verb (light verb) shows distinguishing features in Magahi. This following section shows how Magahi is different from most of the South-Asian languages such as Hindi, Punjabi, and Marathi in terms of complex predicate.

\subsection{Agreement with non-overtly present addressee}

Verbs and non-overt addressee (argument) engage in agreement in Magahi. When the sentence carries the subject in first person, the verb (transitive) shows agreement with the object in honorificity which is not overtly present in the sentence, as in (23) and (24).

\section{3. ham madad karaliain}

I help do.pt.H

'I helped him.'

24. ham kahli-ain ki cal jaa

I said-H that walk go

'I said him (honorific) to go.'

In (23), the light verb karalian 'did' of complex predicate madad karaliain 'helped' agrees with the argument which is not present in the sentence. The light verb occurs in third personhonorific form which agrees with the non-overt object (in third person-honorific form) of the sentence. In example (24), the verb kahli-ain 'said-H' agrees with honorific third person object which is not overtly present in the sentence. It is not agreeing with the subject which is in first person.

\subsection{Listener acting as a silent participant in agreement}

Magahi syntax involves an abstract entity like an 'addressee component' which gets into the agreement system (Verma 2002). This addressee component has the force through which the listener acts as a silent participant or witness to the thing which is stated. This can be better explained with the help of examples given below in (25).

25. a. ham okraa maraliyo

I him.NH beat.H

b. ham okraa maraliau

I him.NH beat.NH 
c. ham unkhaa maraliyo

I him.H beat.H

\section{d. ham unkhaa maraliau}

I him.H beat.NH

'I beat him.'

In example (25), the agreement is neither with subject nor with object but depends on the listener to whom the sentence is stated. As we can see in (25a), the verb carries honorific marker for non-honorific object. In the same way in example $(25 \mathrm{~d})$, the verb carries nonhonorific marker for honorific object. Thus, in this case the agreement depends on the listener of the sentence.

In the same way, the light verb in Magahi complex predicate agrees with the listener of the discourse/ sentence in person and honorificity. In such cases listeners act as silent participant in agreement system in Magahi. This is explained with examples in (26a-b).

\section{6. a. ham bharat ke pardhanmantri ke dekh ke khus holiain}

I India of prime minister.H of see of happy be.pt.H

'I became happy on seeing the prime minister of India.'

b. ham baRii din baad daiiwaa ke dekh ke khus holiain

I very day after maid.NH of see of happy be.pt.H

'I became happy on seeing the maid after such a long time.'

In example (26a-b), the light verb holiain 'be.pt.H' neither agrees with the subject nor object of the sentence but rather agrees to the listener of the sentence who acts as a silent participant in the agreement feature.

\subsection{Case markers as opaque in agreement system}

Argument carrying case markers has no effect on the agreement in Magahi. The verb agrees with the case marked subject in person and honorificity. One of the reasons behind it is the absence of inflections based on gender in Magahi. This shows no role of case markers in agreement in Magahi. The light verb agrees with the argument in person and honorificity, as in (27), (28) and (29).

\section{7. unkhaa se ii cTThii likhal gelain}

he.H by this letter write go.pt.3.H

'The letter was written by him.'

28. raam ke bhuukh lagal haii 
Ram dat hunger feel be.3p.NH

'Ram is hungry.'

29. raajaa ke hamaraa se laRaaii ho gelain

Raja of servant by fight be go.perf.H

'The king got quarreled with me.'

In example (27), the passive light verb gelain agrees with the subject of the sentence irrespective of the case marker se 'by' in person and honorificity. In example (28), the auxiliary verb haii 'be.3p.NH' agrees with the subject 'Ram'. In example (29), the agreement is between raajaa 'king' and passive verb gelain 'go' in person, i.e. third person and honorificity.

\section{Structural Representation of Agreement in Magahi Complex Predicate}

Complex predicate is a single syntactic unit. The structure below in the theoretical framework of Principles and Parameters explains this. The structure of complex predicate in Magahi is shown in the following formula: Complex Predicate $=$ V1/N/A [=/- stem alternation $]+$ V $2+$ Inflectional affixes. The agreement in Principles and Parameters frameworks occurs at spechead configuration.

30. a. mohan saadii karle-taii

Mohan marriage do take-Fut.NH

'Mohan will get married.'

30. b.

IP (TP + Hon.)

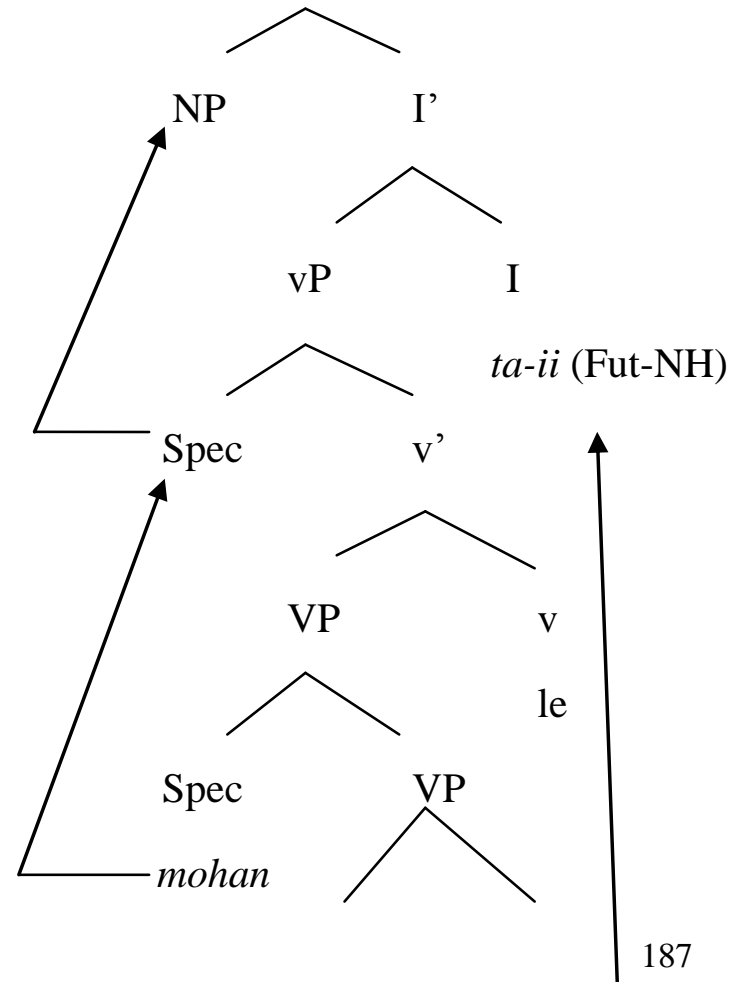




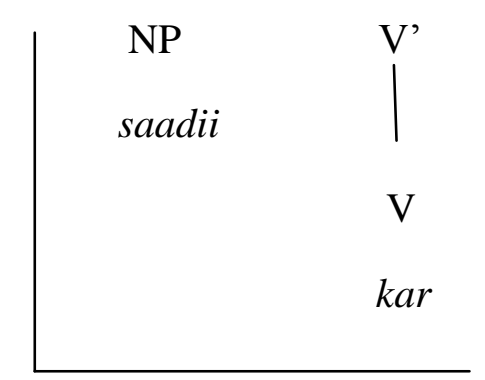

The example in (30a) has a structural representation in (30b). In example (30) the agreement takes place between subject 'Mohan' and light verb letaii 'will take'. The inflection marker ta-ii which carries the agreement features (person and honorificity) occurs in the head position (I) of the inflectional phrase (IP). The subject 'Mohan' moves from spec position of VP to spec position of $\mathrm{vP}$ and then to the spec position of IP to show the agreement. As noun must be in the spec position of IP to agree with elements at I.

31. a. ham apne ke jaae deliain

I you Acc go give.H

'I let you go.'

31. b.

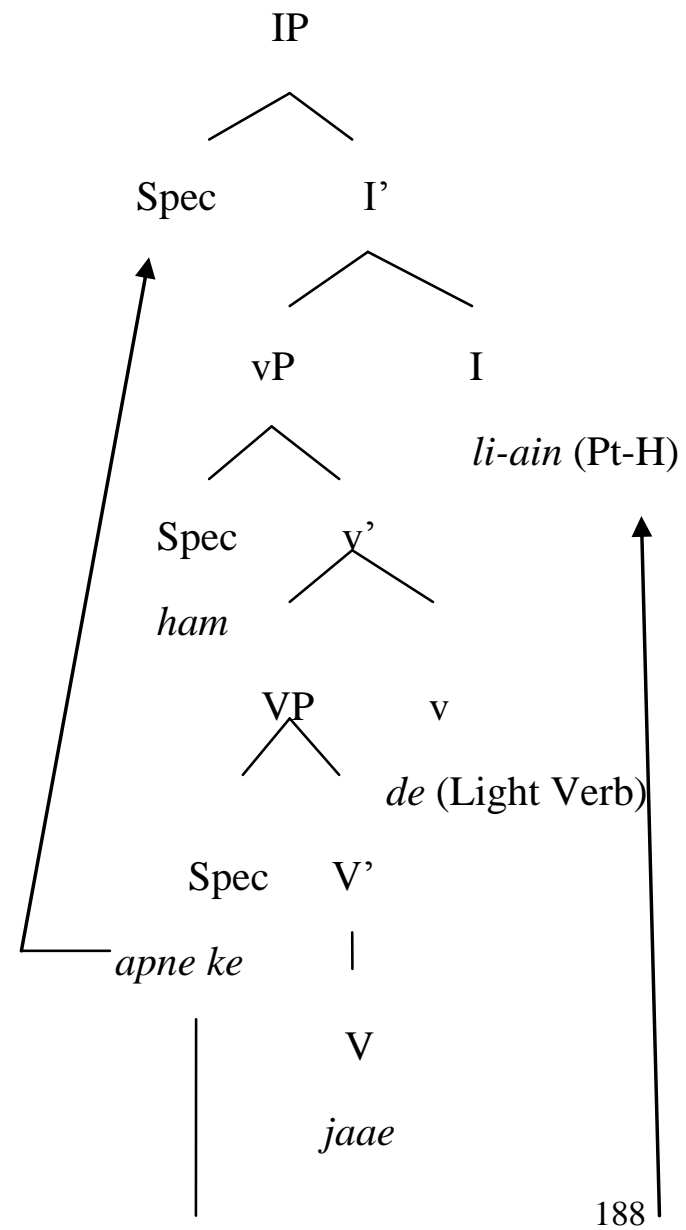


The example in (31a) has a structural representation in (31b). In example (31) the agreement takes place between object and light verb. The inflection marker which carries the agreement features (person and honorificity) occurs in the head position (I) of the inflectional phrase (IP). The object apne ke 'you' moves from spec position of VP to the spec position of IP to show the agreement. As noun must be in the spec position of IP to agree with elements at I. So object noun apne ke moves from the spec position of VP to the spec position of IP to show the agreement.

\section{Conclusion}

In Magahi complex predicate construction, the light verb shows agreement with either subject or object. Agreement is with respect to person and honorificity or non-honorificity of the addressee component. Magahi shows three unique features in context of agreement. In context of Magahi complex predicate, the agreement takes place between light verb and nonovert addressee in the sentence. The agreement is also between the light verb and the listener to whom the sentence is stated. In Magahi, listener acts as a silent participant in agreement. Case markers are opaque in agreement feature. There is no role of case markers in context of Magahi agreement system. All these features make Magahi as unique among other IndoAryan languages. Thus we can say that the agreement system in Magahi depends on the three facts: case markers are opaque to agreement, the role of addressee component, and honorificity factor involved to listener and speaker. Along with these facts the agreement is also based on person. Magahi agreement system functions in the same way in case of complex predicate as with simple verb. Thus, the paper discusses the features of agreement in Magahi, elements of agreement in Magahi, uniqueness in Magahi agreement, structural representation of agreement in Magahi complex predicate.

\section{References}

Baker, M. C. (2008). The Syntax of Agreement and Concord. UK: Cambridge University Press. http://dx.doi.org/10.1017/CBO9780511619830

Bhatt, R. (2008). N-V compounds and Agreement. EFLU, Hyderabad. [Online] Available: people.umass.edu/bhatt/papers/eflu-aug18.pdf

Butt, M. (1995). The Structure of Complex Predicates in Urdu. Stanford: CSLI.

Deoskar, T. (2006). Marathi Light Verbs. Proceedings of the 36th Annual Meeting of the Chicago Linguistics Society, 42(2), 183-198. Chicago

Hook, P. E. (1974). The Compound Verb in Hindi. Ann Arbor: Center for South and Southeast Asian Studies.

Mahajan, A. (1989). Agreement and agreement phrases. M.I.T. Working Papers in Linguistics. 10, 217-252. 


\section{Macrothink}

International Journal of Linguistics

ISSN 1948-5425 2013, Vol. 5, No. 1

Mahajan, A. (1992). The Specificity Condition and the CED. Linguistic Inquiry, 23(3), 510516.

Verma, M. K. (1993). Complex predicates and light verbs in Hindi. In M. K. Verma (Ed.), Complex Predicates in South Asian Languages. New Delhi: Manohar Publishers.

Verma, M. K. (2002). Exploring the Parameters of Agreement: The Case of Magahi. Language Sciences, 13(2), 125-143. http://dx.doi.org/10.1016/0388-0001(91)90010-X 